LETTER FROM THE EDITORS

Volume 1 (2020), No. 1, pp. iii-iv

DOI: $10.15367 /$ ch.v1i1.307

\title{
Letter from the Editors
}

Molly Beiting, MA, CCC-SLP1, Hamlet Gasoyan, DMD, $\mathrm{MPH}^{2}$, Jennifer K. Ibrahim, $\mathrm{PhD}^{2}$, David B. Sarwer, $\mathrm{PhD}^{3,4}$, Jacqueline C. Spitzer, MSEd ${ }^{4}$

${ }^{1}$ Department of Communication Sciences and Disorders, Temple University College of Public Health

2 Department of Health Services Administration and Policy, Temple University College of Public Health

${ }^{3}$ Department of Social and Behavioral Sciences, Temple University College of Public Health

${ }^{4}$ Center for Obesity Research and Education, Temple University College of Public Health

We are delighted to welcome you to the inaugural issue of CommonHealth, an interdisciplinary, peer-reviewed, open-access journal of the College of Public Health at Temple University.

Establishment of this journal is an exciting milestone and a natural next step in our trajectory of growth and leadership in public health education and research. The College of Public Health $(\mathrm{CPH})$ is home to more than 50 academic programs within 17 disciplines. Our departments have earned 24 program-specific accreditations and four of our graduate programs are within the top $25 \%$ nationwide. In 2017, the College received full accreditation by the Council on Education for Public Health. One of the key differentiators of $\mathrm{CPH}$ is our active research community and commitment to interdisciplinary research and education. In 2018, the work of CPH investigators was supported by over $\$ 22$ million dollars in funding. Students at every level in CPH participate in meaningful collaborations with faculty, receive hands-on research training, and produce impactful research.

A dedicated journal is the ideal vehicle to build on the success of the College and showcase the impressive research, teaching innovations, and practice insights of our students and faculty. In the Winter 2019, a committee was formed to explore the best way to develop a student-faculty collaboratively run journal. The committee decided to prioritize an open-access online format for rapid dissemination of high-quality content. The committee also established a representative editorial board, with emphasis on student participation and membership from each of the College's department. These aims align with the CPH's mission to promote transdisciplinary collaboration and develop the next generation of leaders in research, scholarship, service, and innovation. The committee also emphasized the need for shared governance with students so that the administration of the journal could serve as a training opportunity as well.

CommonHealth will be published regularly, featuring content of interest to public health scholars in academic, clinical, government, and industry roles working on all aspects of current and emerging public health issues. This inaugural issue includes work from $\mathrm{CPH}$ faculty and students 
in a form of original research papers, a research letter, as well as conference proceedings from the 2019 CPH Research and Evidence Based Practice Day. These articles represent the truly ground-breaking work being conducted by our students and faculty.

Many thanks are owed to the people who have so generously given their time and expertise to bringing this project to fruition. This journal would not be possible without the guidance of the Dean of the College of Public Health, Dr. Laura A. Siminoff. Dr. Siminoff's vision and leadership are largely responsible for elevating the College to its current position and ability to support a publication of this nature. We also thank staff of the Temple University Libraries and the CPH Communications and Marketing team for their critical support in building our open source publishing platform.

Looking forward, CommonHealth plans to grow our Editorial Board, with a specific focus on increasing representation from accomplished professionals from various disciplines in public health education and research. We will work tirelessly to expand the indexing and research dissemination routes for the Journal. Finally, the editorial team will continue to adhere to the highest quality standards and ethical principles of academic publishing and review.

We are cordially inviting authors from Temple University and the public health community at large to submit their original research, research commentary, clinical innovation and practice, teaching innovation and practice, community connection articles, and multimedia submissions to CommonHealth. We look forward to seeing your scholarship.

With gratitude,

The CommonHealth Editorial Team 